\title{
Real-world Treatment Patterns of Lung Cancer- experience of Resource Restricted Country
}

Ivane Kiladze ( $\boldsymbol{D}$ ivane6@hotmail.com )

Research Institute of Clinical Medicine after Ac. F.Todua https://orcid.org/0000-0003-1553-3670

\section{Elene Mariamidze}

Research Institute of Clinical Medicine after Ac. F.Todua

\section{Branislav Jeremic}

Research Institute of Clinical Medicine after Ac. F.Todua

\section{Research in practice}

Keywords: lung cancer, Georgia, radiotherapy, systemic treatment

Posted Date: October 6th, 2020

DOl: https://doi.org/10.21203/rs.3.rs-74093/v1

License: (c) (i) This work is licensed under a Creative Commons Attribution 4.0 International License. Read Full License 


\section{Abstract}

\section{Background:}

Lung cancer (LC) continues to be a significant worldwide public health issue. In recent years there have been several publications addressing specifics of LC worldwide, but none concerning Georgia- country with high number of smoking population and LC cases. We conducted the first study in Georgian population, that aims current LC practice.

\section{Methods:}

The aim of the study was to provide an overview of treatment of LC, with discussion situation in this field and indicating the future strategies for improved cancer care in the country. Medical, radiation and surgical oncologists providing treatment of LC in main hospitals $(n=13)$ over the country, filled questionnaire that addressed specific information regarding the treatment aspects of LC reflecting current surgical aspects, systemic treatment and radiotherapy (RT).

\section{$\underline{\text { Results }}$}

There is no national screening program, while radiologic imaging is readily available. The vast majority of patients in the country present with advanced stages at diagnosis and they are treated with systemic therapy and/or RT.

The surgical treatment is largely underutilized with the differences being observed among surgeons on the optimal timing and the extent of surgery, as well as role of surgery in specific clinical situations.

Improved health care system, well equipped hospitals, availability of many anticancer drugs and existence of modern RT technology, are coupled with slow appearance of country-adapted guidelines and protocols as well as enforcing MDT meetings.

There is limited access to expensive novel agents, psychological support and high quality palliative care.

\section{Conclusions}

There is still much work to be done, with all above steps considered mandatory to improve effectiveness and quality of care of LC patients.

\section{Highlights}

- Lung cancer has high prevalence in low- and middle-income countries (LMICs)

- Almost $90 \%$ of LC patients in the country present with advanced stages (III-IV) with $60 \%$ of patients having stage IV disease at diagnosis

- Limited ability in access to biomarker testing as well as modern therapeutics 
- Little number of patients receive immunotherapy outside of clinical trials

- Urgent need of implementation of country-adapted diagnostic and therapeutic guidelines and protocols as well as enforcing MDT meetings

- Continuous professional development, including accredited training programs in thoracic surgery, increasing oncology fellowship programs and supporting investigator-initiated trials should lead to improved LC care effectiveness

- Enrollment in clinical trials that further enhances the development of tailored therapies is widely recognized as advantageous and is highly recommended at all stages of treatment

- A collaborative effort could help overcome some common barriers.

\section{Background}

Lung cancer (LC) is the most common malignancy responsible for 1.8 million of deaths worldwide [1]. In Georgia LC alone accounts for $13 \%(n=1217)$ of incident cases in both sexes. In males incidence of LC was 1041 (32.4/100000) which accounts $20 \%$ of all cancers in men [2].Georgia is an Eastern European, middle-income country with 3.7 million residents and one of the highest number of active smokers in the European Region [3, 4]. Georgia lacks an LC screening program for smokers and partially because of this, the majority of LC patients present at an advanced stage. The National Centre for the Disease Control (NCDC) showed that almost $90 \%$ of LC patients in the country present with advanced stages (III-IV) with $60 \%$ of patients having stage IV disease at diagnosis [5]. Still, data from the US show that deaths from LC are declining in large part due to successful treatment options including targeted therapies and immunotherapy [6]. In light of the rapidly changing landscape in the diagnosis, staging, and treatment of LC, we thought to define the state of practice in Georgia by convening specialists who treat LC across 13 institutions in our country with the goal to describe differences in access and approaches to LC.

\section{Methods}

We gathered key opinion leaders within our institution to define consensus staging and work-up protocols for people with lung cancer. At our center, all patients undergo CT scans followed by biopsy for diagnosis; a PET-CT is recommended, but its use is limited due to financial constraints on patients. After this, patients are presented to the multidisciplinary team (MDT) for the final treatment decision-making. Our internal data were used to generate an interdisciplinary survey, consisting of both open-ended and single best choice answer questions (18 questions related to medical management, 38 questions related to radiation therapy, and 11 questions for surgical treatment), with separate sections for non-small cell (NSCLC) and small cell (SCLC) cancers. Surveys were distributed to providers across 13 high-volume cancer institutions and across cancer specialties throughout the country. Survey data was collected and descriptive statistics used to present the results. The study was internally reviewed during a regularly scheduled scientific development review at our center in the absence of an Institutional Review Board.

\section{Results}


The survey went out to a total of 24 physicians representing medical oncology $(n=13)$, radiation $(n=7)$ and surgical thoracic oncologists $(n=4)$ and all responded. Thirteen were male and 11 were female; all had been in practice for over 5 years. All medical oncologists practiced general rather than thoracic specific oncology.

\section{Surgical Approaches:}

The case volume varied between our surgeons ranging from less than $4 /$ month to over 20 /month. Although all patients in Georgia have access to surgery, it is not performed at diagnosis for the vast majority due to diagnosis at a later stage. Three of the four surgeons did not have access or use a MDT conference.

Regarding the treatment of early stage LC, only 2 performed video-assisted thoracoscopy (VATS). Three of them performed systematic lymphadenectomy; the fourth preferred lymph node (LN) sampling. When asked about the role of surgery in oligometastatic NSCLC, two did not offer surgery and two did so but only in selected patients, mostly in case of single brain or adrenal metastasis. In addition, two offered surgery for patients presenting with bulky T4 NSCLC, while the other two did not. All surgeons would consider neoadjuvant chemotherapy (CHT) or RT-CHT, followed by either pneumonectomy or lobectomy/bilobectomy in medically fit patients.

There are extremely few cases of early stage SCLC in the country and two of the four surgeons reported seeing less than 3 surgical cases/annually. Both do not offer surgery for SCLC.

\section{Systemic Therapy:}

All medical oncologists $(n=13)$ reported a limited ability to prescribe targeted treatments, mostly due to the costs; however, chemotherapy is widely available. While all had access to diagnostic biomarkers for lung cancer, testing for epidermal growth factor receptor (EGFR), anaplastic lymphoma kinase $(A L K)$ and programmed death ligand-1( $P D-L 7)$ was not routinely used due to limitation in access to modern therapeutics. Notably, while molecular testing is available, it is performed on a send-out basis.

Despite these limitations, all medical oncologists (13 out of 13) would recommend EGFR testing, with ALK and ROS1 testing recommended by 8 and 7 clinicians, respectively. Nine felt testing for PD-L1 over expression was warranted; only two of them recommended testing for KRAS mutation. [Fig.1].

Patients with driver mutation can access to several TKIs within the public health system, albeit with only partial funding. We found that only approximately $16 \%$ (range, $0-30 \%$ ) of EGFR mutated patients received first-generation TKIs; with even less access to $2^{\text {nd }}$ or $3^{\text {rd }}$ generation agents.

In our survey, five out of 13 respondents had no access to clinical trials. Most clinical trials were evaluating immunotherapy, with an average of two per center (range, 0 to 5). We identified that a high 
percentage (39.5\%) of patients with lung cancer accessed these opportunities (range, 0-95\%). Only a very little number of patients receive immunotherapy outside of clinical trials- average, 2 patients (range, 0-5) annually reflecting the lack of access to immunotherapy drugs.

The survey reported almost universal administration of platinum-based therapy for patients with wild type, advanced-stage NSCLC in Georgia. Paclitaxel/carboplatin, cisplatin/gemcitabine, cisplatin/pemetrexed, carboplatin/docetaxel, or carboplatin/pemetrexed were regimens in common use [Fig. 2].

For metastatic squamous cell NSCLC most frequently used regimen in $1^{\text {st }}$ line setting is cisplatin/gemcitabine (76\%), followed by paclitaxel/carboplatin (38\%). In non-squamous histology most institutions use paclitaxel/carboplatin (54\%), and then platinum compounds with pemetrexed (23\%).

Platinum plus etoposide chemotherapy is the cornerstone regimen in the treatment of patients with SCLC. Cisplatin with etoposide is mostly used combination in both LD- and ED-SCLC, $77 \%$ and $54 \%$ respectively. In most institutions platinum/etoposide $\mathrm{CHT}$ combined with thoracic RT is the choice for patients with limited disease (LD SCLC), while CHT alone is used in patients with extensive disease (ED SCLC) followed by TRT in responders. Other regimens used in ED-SCLC in first line setting are combination of carboplatin/etoposide and cisplatin with either topotecan or irinotecan.

\section{Radiation Therapy:}

Seven of 13 institutions offered RT. Six out of 7 responding institutions house megavoltage linear accelerators (Linacs), while only one institution houses a single Cobalt machine capable of performing 3D RT. These external beam machines are coupled with brachytherapy and fully equipped medical physics equipment, in addition to available CT and MRI scans. Two institutions have access to PET-CT for treatment planning. None of the 7existing RT departments use brachytherapy in the treatment of lung cancer, either alone or in combination with other treatment modalities. The vast majority of institutions use triple $A(A A A)$ planning algorithms for the treatment of lung cancer. All institutions frequently use adaptive RT, re-planning being done after two/thirds to three/fourths of the planned total RT dose being given, if satisfactory response to initial part of the RT is observed. Two institutions having access to PETCT occasionally use it for adaptive RT planning.

For people with early (Stage I-II) NSCLC,all institutions use 3D conventionally fractionated (CF) RT.Indications to use RT in this setting include technically operable but medical inoperable cases, those deemed elderly/frail as well as occasional patient who refuse surgery. Total doses of RT range from hypofractionated $55 \mathrm{~Gy}$ in 20 daily fractions to CF 60-70 Gy in 30-35 daily fractions. Target volumes always include visible tumor with or without lymph nodes and only in one case incorporate elective nodal irradiation. Three out of seven departments use stereotactic body RT (SBRT) in Stage I NSCLC with total doses given ranging from $27 \mathrm{~Gy}$ in 3 fractions to most commonly given 50 Gy in 5 fractions but also including $60 \mathrm{~Gy}$ in 8 fractions, all depending on the tumor location. Various means of tumor motion 
control is in use in these centers and is considered mandatory. Postoperative RT is instituted after surgery in early stage NSCLC due to various reasons such as positive surgical margins ( $R+$ ), pN2, extracapsular extension (ECE) in all institutions but at an extremely low rate. Total RT doses are 50-54 Gy given with a CF and only two departments use 60 Gy CF. In locally advanced (Stage III) NSCLC, four departments would not consider any surgical multimodality approach, while of the other three, two specified patients with low tumor volume or single mediastinal LN station as potential candidates for induction CHT or RT$\mathrm{CHT}$ followed by surgery as their treatment option. Of the latter group, one even specified as potentially suitable patients those with bulky tumors presumably not being curable with exclusive high-dose concurrent RT-CHT. In a non-surgical scenario, 5 out of 7 departments would prefer concurrent RT-CHT, while one would also consider induction $\mathrm{CHT}$ followed by either RT or concurrent RT-CHT depending on the patient's PS. When however, asked when they would consider induction CHT followed by either RT or concurrent RT-CHT, they mostly preferred induction $\mathrm{CHT}$ in bulky $\mathrm{T}$ and/or $\mathrm{N}$ due to fear of concurrently giving CHT with "too" large RT fields leading to more toxicity as well as when extensive symptoms and poor PS are expected to resolve with CHT before RT. Contrary to these, the responders would consider concurrent RT-CHT in non-bulky tumors and young and fit patients with a good PS. Total doses and fractionation used in this setting included CF 60-70 Gy always given on all visible tumors only. In cases of Pancoast tumors, preferred approach in all but one department would be exclusive concurrent RT-CHT (i.e. no surgery at all), and only one institution would consider preoperative RT-CHT followed by surgery as an option. When asked about surgery in cases of bulky tumors invading major intrathoracic structures, none of the respondents specified it would be an agreeable solution on a MDT meetings. In symptomatic Stage IV patients, responders would treat all existing symptoms. Thoracic RT would be used with total doses of 20 to 50 Gy given in 5 to 20 fractions and only a single department would consider 60 Gy in 30 fractions in this setting. Four out of seven institutions recognized specifics of "oligometastatic" disease, but the number of metastasis deemed as appropriate for this designation varied between up to 3 and up to 5 . Dose and fractionation of oligometastases greatly varies. Brain metastases were mostly treated with stereotactic radiosurgery (SRS) (15-24 Gy in a single fraction), while non-brain metastases located in various organs and tissues were treated with dose/fractionation regimens from 18-24 Gy in 1-3 fractions to $27 \mathrm{~Gy}$ in 3 fractions or to30 Gy in 6 fractions or even to 50 Gy given in either 5 or 10 fractions, given sometimes on alternate days. When asked in which cases of LC metastatic to lung parenchyma they would consider surgery as the treatment of choice, two departments would never suggest it, other citing ipsilateral metastases only, fit patients only, single ipsilateral/lobar metastases and primary controlled with a few (though not specified) lung metastases.

In LD SCLC domain, five departments would consider starting concurrent part of the combined RT-CHT approach during either the first or the second cycle of $\mathrm{CHT}$, one department preferring the third cycle of $\mathrm{CHT}$ while only one department opted for sequential CHT-RT approach with RT starting afther the fourth $\mathrm{CHT}$ cycle. In cases when RT starts with the $\geq 2$ cycle of $\mathrm{CHT}$, only one department would use pre-CHT volumes to be treated. Dose and fractionation included either $45 \mathrm{~Gy}$ in 30 fractions in 15 treatment days (1.5 Gy bid) ( $n=3)$ or 60-70 Gy in 30-35 daily fractions $(n=2)$ while two departments were using both regimens without clearly specifying preferences for the use of either of these two. All seven departments 
use prophylactic cranial irradiation ( $\mathrm{PCl}$ ) after the end of complete RT-CHT, allowing one month after it for the evaluation of response. Dose of $25 \mathrm{~Gy}$ in 10 daily fractions was used in six departments of which only one allowed 20 Gy in 5 daily fractions, while the sole RT department practices 30 Gy in 10 daily fractions. All seven departments use thoracic RT in ED SCLC and do that after 3 cycles of CHT $(n=3)$ or after 4-6 cycles of CHT (n=4). Four out of six would use thoracic RT given concurrently with CHT, two departments would practice sequential CHT and RT approach, and one department would use both. Thoracic RT doses and fractionation used in this setting included $45 \mathrm{~Gy}$ in 15 daily fractions $(\mathrm{n}=2), 46-54$ Gy in 23-24 daily fractions ( $n=1), 30$ Gy in 10 fractions $(n=2), 60$ Gy in 30 fractions $(n=1), 30$ to $40-45$ Gy in 10-15 fractions $(n=1)$ and 50-60 Gy in 2 Gy daily fractions $(n=1)$. Target volumes included visible tumor in six and pre-CHT volumes in one case. Three institutions do not use PCl after RT-CHT and four use it after RT-CHT was finished (allowing a gap of 1 month), PCl being given in cases of CR at both intrathoracic and distant sites. When used PCl was given in $25 \mathrm{~Gy}$ in 10 daily fractions while only one department also allowed 20 Gy in 5 daily fractions.

\section{Discussion}

In this investigation, the very first one of the patterns of practice in LC in Georgia, we have assembled as many institutions as possible. Six of them offer only $\mathrm{CHT}$ treatments, and the remaining seven are capable of administering both RT and $\mathrm{CHT}$. Due to non-existing accredited training programs in thoracic surgery, and limited number of surgeons treating LC we have surveyed only those surgeons known to us as having substantial experience in LC surgery. While this may be a disadvantage of our survey, these surgeons are attending MDT meetings in LC and are actively contributing to the whole decision-making process; hence, our data reflect our own ("real world") situation. To extend this, we were able to collect the data from all but one (Batumi) centers who offer both RT and $\mathrm{CHT}$, again, reflecting the real treatment scenario on a national level.The changes in country's health care system in the past 10-15 years had dramatically improved many aspects of LC treatment. Contrary to previous periods, there is now abundance of well equipped hospitals around the country. Many young oncologists have regularly participatedin training and fellowship programs abroad, while various international oncology conferences were organized in Georgia, all helping improve knowledge and skills in LC.

In the largely underutilized surgical treatment domain, differences were observed among surgeons on the optimal timing and the extent of surgery, as well as role of surgery in specific clinical situations such as bulky T4 NSCLC disease and LD-SCLC. While prevalent advanced stages detected worldwide limits its use to some $20-25 \%$ of all LC cases worldwide, the situation in Georgia is much worse where almost $90 \%$ of all patients are inoperable. Hopefully, with future establishment of screening programs and widespread,better diagnostics the number of surgical candidates would rise. Not to be forgotten, expected rise of the patient numbers would also request for a timely preparation of the thoracic surgery community as to be able to implement modern surgical aspects such as VATS.

The majority of medical oncologists in Georgia usually refer to the National Comprehensive Cancer Network (NCCN) and to a lesser extent to the European Society for Medical Oncology (ESMO) guidelines. 
Using international guidelines and recommendations in daily practice makes treatment more modern and standardized in whole country. Some hospitals begin implementation of MDT meetings, which is relatively new practice and more and more patients receive their treatment based on team decision [7].

Targeted therapies and ICBs provide effective and tailored options for patients with NSCLC. International guidelines for NSCLC recommend that all patients with metastatic adenocarcinoma should have their tumor tissue tested for actionable driver mutations [8]. However, molecular testing generally is employed at the discretion of the treating oncologist in the country. As in many Eastern European countries there is somewhat limited access to all molecular profiling platforms of the tumor at a large scale [9]. Although it is more available in some countries and tertiary centers of excellence, many patients will not realize the full benefits of precision oncology.

For the first line, of the Food and Drug Administration Agency (FDA)-approved agents used for patients with advanced or metastatic NSCLC with mutations in EGFR (EGFR-TKIs), only erlotinib is available in the country with patient co-payment. Management challenges are related to the difficulty in accessing the most recent targeted and immunotherapy agents due to the high cost and lack of reimbursement from insurance companies. There are limitations for the use of the newer $\left(2^{\text {nd }} / 3^{\text {rd }}\right)$ generations of TKIs. However, some programs of Tbilisi City Hall and the Ministry of Health $(\mathrm{MoH})$ help partially cover $3^{\text {rd }}$ generation TKI drug osimertinib which significantly improves PFS when compared with gefitinib or erlotinib [10].

Regarding $\mathrm{CHT}$ aspects, combination of paclitaxel and carboplatin is the most common regimen for nonsquamous NSCLC, followed by combination of platinum compounds with pemetrexed, likely because the latter is found to have a statistically significant improvement in OS compared to cisplatin plus gemcitabine [11]. Some institutions use pemetrexed maintenance therapy based on the PARAMOUNT study, which found a significant reduction in the risk of disease progression, improved OS and increased PFS [12,13]. Most frequently used regimen for metastatic squamous cell NSCLC in $1^{\text {st }}$ line setting is cisplatin/gemcitabine and it is used based on a subgroup analysis of a noninferiority trial in which it showed significant OS improvement versus cisplatin/ pemetrexed [11].

In the treatment of SCLC, the standard first-line systemic treatment remains a combination of cisplatin/etoposide, similarly to the rest of the world, but with only limited national access to atezolizumab [14]. Immunotherapy drugs are not reimbursed in Georgia, neither in first- nor in subsequent lines, although the drugs are registered and available at the patient's expense. Despite this fact some patients receive ICBs by enrollment in clinical trials.For two decades clinical research has been growing steadily in the country and participating in trials are the only way for patients to get novel treatment drugs.

Our survey shows that many hospitals don't have even one clinical trial. Generally, despite increase, the number of ongoing clinical trials with novel targeted therapies and immunotherapy in Georgia is quite low, leading to delayed access to new drugs. Enrollment in clinical trials that further enhances the 
development of tailored therapies is widely recognized as advantageous and is highly recommended at all stages of treatment [15].

Regarding RT aspects, there is a total of 15 external beam machines of which 13 are functional.Georgia belongs to lower-middle income countries with no prevention, screening and early detection in LC, where approximately $90 \%$ of all patients are diagnosed in advanced (III or IV) stage. This would likely indicate the scenario of under equipment as international estimates for limited resource setting $[16,17]$ would indicate the need for additional 4-6 functioning external beam machines. In addition, of 7 existing centers offering RT services, 5 are located in its capital, Tbilisi, with the obvious need for facilities in distant regions of the country.

In cases of NSCLC, RT is employed in early (Stage I-II) cases either as 3D or 4D conventionally fractionated RT or SBRT. Indications for its use and dose/fractionation regimens changed a little in the past 20 years [18]. Similarly, SBRT regimens employed in 3 out of 7departments used several widely practiced fractionated regimens depending on the tumor location [19-21]. Recent data on the use of modern postoperative TRT [22] seem to overcame negative impact of historic data [23,24], since it enabled effectively concentrating on patients harboring high risk features. In Stage IIIA NSCLC, less than a half of the institutions would still consider surgical multimodality approach likely due to a number of group/society guidelines and recommendations $[25,26]$ in spite of the fact that serious criticism and a number of flaws and fallacies have been highlighted in recent years [27-30]. In, inoperable cases, the vast majority of departments would prefer concurrent RT-CHT, following highest level of evidence existing for more than a decade [31-33]. Only big and bulky tumors led two departments to consider induction CHT followed by either RT or RT-CHT, due to expected significant acute side effects of exclusive concurrent RT$\mathrm{CHT}$. All institutions treat only visible tumors. Although majority of institutions nowadays use $60 \mathrm{~Gy}$, some suggested $70 \mathrm{~Gy}$, in contradiction to recent results of the Radiation Therapy Oncology Group (RTOG) 0617 [34]. In cases of Pancoast tumors, only one institution opted to preoperative RT-CHT followed by surgery. This seems to reflect both few experienced and practicing thoracic surgeons in the country, lack of accredited training programs as well as lack of experience the vast majority of existing surgeons seems to suffer seemingly due to low volume LC surgeries nationwide. In symptomatic stage IV patients, RT would be used to treat all existing symptoms withonly one institution offering 60 Gy in 30 daily fractions in this setting. Following general and worldwide trends [35,36], the majority of institutions would follow currently accepted RT approach in "oligometastatic" disease, although their consideration seems to reflect current uncertainties. Dose and fractionation depended on the number of metastases, metastatic site, primary tumor histology, following major evidences worldwide [37-39].

In cases of LD SCLC, majority of departments confirmed policy to start RT concurrently as early as possible [40]. Choice of RT fields also follows general trends in being based on post-CHT volumes, except when RT starts concurrently with the first cycles of $\mathrm{CHT}$. While majority of institutions use either hypo- or hyper fractionated RT, some institutions still use CF RT with doses as high as $70 \mathrm{~Gy}$, contradicting accumulated evidence [41-44]. When PCl is considered, institutions seems to have firmly adopted 20-year old results of meta-analysis [45]. Doses and fractionation of PCl are also in concordance to existing 
recommendations [46]. Institutions request response evaluation after 1 month after the end of $\mathrm{CHT}$, after which MRI is usually used for choosing patients suitable for PCI (all CR and good PR). In cases of ED SCLC, pivotal study of Jeremic et al [47] and following study of EORTC [48] were seemingly strongest advocates for the use of thoracic RT since all departments use it, in spite of disappointing results of the RTOG 0835 study [49]. The vast majority of institutions would give RT concurrently with CHT similarly to Jeremic et al [47] and only occasionally sequentially as per EORTC [48]. A variety of dose/fractionation regimens were used, likely reflecting lack of consensus on the optimal dose/fractionation aspects in this setting. Similarly to LD SCLC, the vast majority of institutions would use visible (post-CHT) RT volumes. The use of PCI in ED SCLC left institutions almost split between using it or not, likely reflecting impact of recent Japanese data [50] that challenged EORTC study results [51]. When given, PCl was administered after brain imaging done one month post-CHT showed $\mathrm{CR}$ on both intrathoracic and distant sites.

\section{Conclusion}

Georgian health care system improved over the past years and followed the trends observed in the rest of the European Region. Availability of anticancer drugs and existence of modern RT technology with increasing thoracic oncologists' knowledge and skill, are coupled with slow appearance of countryadapted diagnostic and therapeutic guidelines and protocols as well as enforcing MDT meetings. However, Georgian patients with LC still suffer from shortcomings when considering several aspects pertaining to their LC care. Continuous professional development, including accredited training programs in thoracic surgery, increasing oncology fellowship programs and supporting investigator-initiated trials should lead to improved LC care effectiveness. Also, psychological support and high quality palliative care, currently hardly -existing, are deemed especially important for the country. There is still much work to be done, with all these steps considered mandatory to improve effectiveness and quality of care of LC patients.

\section{Abbreviations}

LC-Lung cancer

RT- radiotherapy

NCDC- The National Centre for the Disease Control

CT- Computed Tomography

PET-CT- Positron Emission Tomography - Computed Tomography

MDT- multidisciplinary team

NSCLC- non-small cell lung cancer

SCLC - small cell lung cancers 
VATS- video-assisted thoracoscopy

LN- lymph node

CHT- chemotherapy

RT-CHT- radiochemotherapy

EGFR- epidermal growth factor receptor

ALK- anaplastic lymphoma kinase

PD-L1- programmed death ligand-1

ROS1- ROS Proto-Oncogene 1

KRAS- Kirsten rat sarcoma viral oncogene homolog

TKIs- Tyrosine Kinase Inhibitor

LD- SCLC limited disease small cell lung cancer

ED- SCLC- extensive disease small cell lung cancer

CF- conventionally fractionated

MRI- Magnetic resonance imaging

SBRT- stereotactic body radiotherapy

Gy-Gray

ECE- extracapsular extension

SRS- stereotactic radiosurgery

PCl- Prophylactic cranial irradiation

NCCN- National Comprehensive Cancer Network

ESMO- European Society for Medical Oncology

ICBs- immune checkpoint blockers

FDA- Food and Drug Administration Agency

MoH-Ministry of Health 
OS- overall survival

PFS- progression free survival

RTOG- Radiation Therapy Oncology Group

\section{Declarations}

\section{Ethics approval and consent to participate:}

Institutional ethics committee waived its consideration/approval as no patient data was included in this multi-institutional practices survey. Written informed consent was obtained from all participants.

\section{Consent for publication:}

NO CONSENT WAS SOUGHT SINCE THERE ARE NO PATIENT DATA INCLUDED IN THIS STUDY (SURVEY OF PRACTICES NOT THE PATIENTS' DATA)

\section{Availability of data and material:}

Only data/material we have is the one provided in questionnaire (suppl.)

\section{Competing interests:}

THE AUTHORS DECLARE NO COMPETING INTERESTS REGARDING THIS STUDY

\section{Funding:}

No funding sources

\section{Authors' contributions:}

Ivane Kiladze- conceptualization, methodology, writing- original draft preparation, data collection; Elene Mariamidze- data curation, visualization, writing- original draft preparation; Branislav Jeremicsupervision, writing-reviewing and editing.

\section{Acknowledgments:}


1) The authors thanks doctors M. Maglakelidze, A. Matitashvili,K. Bibichadze,E. Natelauri, B. Sokurashvili, I. Khubua, N. Pkhakadze, L.Kuchava, D.Giorgadze, Z.Zedginidze, Z.Lomidze, E. Dgebuadze, N. Kalandarishvili, A. Maisuradze, M. Jvania, T.Kortua, L. Gachechiladze, A. Gozalova, T. Gogitidze, R.Sreseli, K.Dzindzibadze, M.Artmeladze and T. Kontselidze for providing information and participating in the development of the manuscript.

2) The authors would like to thank Dr. Don Dizon for thoughtful comments and suggestions which made the publication of this article possible

\section{References}

1. Bray F, Ferlay J, Soerjomataram I, Siegel RL, Torre LA, Jemal A. Global cancer statistics 2018 : GLOBOCAN estimates of incidence and mortality worldwide for 36 cancers in 185 countries [published correction appears in CA Cancer J Clin. 2020 Jul;70(4):313]. CA Cancer J Clin. 2018;68(6):394-424. doi:10.3322/caac.21492

2. The Global Cancer Observatory. IARC. https://gco.iarc.fr/today/data/factsheets/populations/268georgia-fact-sheets.pdf. Accessed May 2019

3. 4Key Indicators. http://www.geostat.ge/index.php?action=0\&lang=eng. Accessed 16 Oct 2017

4. European School Survey Project on Alcohol and Other Drugs: Georgia Country Report, 2016. Tbilisi: National Centre for Disease Control and Public Health of the Ministry of Labour, Health and Social Affairs of Georgia; 2016.

5. Cancer statistics. https://www.ncdc.ge/Pages/User/News.aspx?ID=bec659c0-56a2-4190-9c0ce47a63bcca4f. Accessed 2019

6. Rebecca L. Siegel,Kimberly D. Miller, Ahmedin Jemal. Cancer statistics, 2020. CA CANCER J CLIN 2020;70:7-30.https://doi.org/10.3322/caac.21590

7. Kiladze I, Mariamidze E, Jeremic B. Lung Cancer in Georgia. Journal of Thoracic Oncology, 15 No. 7: 1113-1118.https://doi.org/10.1016/J.JTHO.2020.02.030

8. National Comprehensive Cancer Network (NCCN). Non-Small Cell Lung Cancer V1.2019. Available at https://www.nccn.org. Accessed October 30, 2018

9. Ryska A, Buiga R, Fakirova A, et al. Non-Small Cell Lung Cancer in Countries of Central and Southeastern Europe: Diagnostic Procedures and Treatment Reimbursement Surveyed by the Central European Cooperative Oncology Group. Oncologist. 2018;23(12):e152-e158. doi:10.1634/theoncologist.2018-0008

10. Soria JC, Ohe $\mathrm{Y}$, Vansteenkiste $\mathrm{J}$ et al. Osimertinib in untreated EGFR-mutated advanced non-smallcell lung cancer. N Engl J Med 2018;378:113-125. DOI: 10.1056/NEJMoa1713137

11. Scagliotti GV, Parikh P, von Pawel J, et al. Phase III study comparing cisplatin plus gemcitabine with cisplatin plus pemetrexed in chemotherapy-naive patients with advanced-stage non-small-cell lung cancer. J Clin Oncol. 2008;26(21):3543-3551. doi:10.1200/JC0.2007.15.0375. 
12. Paz-Ares L, de Marinis F, Dediu M, et al. Maintenance therapy with pemetrexed plus best supportive care versus placebo plus best supportive care after induction therapy with pemetrexed plus cisplatin for advanced non-squamous non-small-cell lung cancer (PARAMOUNT): a double-blind, phase 3, randomised controlled trial. Lancet Oncol. 2012;13(3):247-255. doi:10.1016/S1470-2045(12)70063-3

13. Gridelli $\mathrm{C}$, de Marinis $\mathrm{F}$, Thomas $\mathrm{M}$, et al. Final efficacy and safety results of pemetrexed continuation maintenance therapy in the elderly from the PARAMOUNT phase III study. $J$ Thorac Oncol. 2014;9(7):991-997. doi:10.1097/JT0.0000000000000207

14. Leora Horn, Aaron S. Mansfield et al. First-Line Atezolizumab plus Chemotherapy in Extensive-Stage Small-Cell Lung Cancer. N Engl J Med 2018; 379:2220-2229

DOI: 10.1056/NEJMoa1809064

15. NAGLA ABDEL KARIM, KAREN KELLY. Role of Targeted Therapy and Immune Checkpoint Blockers in Advanced Non-Small Cell Lung Cancer: A Review. The Oncologist 2019;24:1270-1284

16. Barton MB, Frommer M, Shafiq J. Role of radiotherapy in cancer control in low-income and middleincome countries [published correction appears in Lancet Oncol. 2006 Oct;7(10):797]. Lancet Oncol. 2006;7(7):584-595. doi:10.1016/S1470-2045(06)70759-8

17. Zubizarreta EH, Fidarova E, Healy B, Rosenblatt E. Need for radiotherapy in low and middle income countries - the silent crisis continues. Clin Oncol (R Coll Radiol). 2015;27(2):107-114. doi:10.1016/j.clon.2014.10.006

18. Jeremic B, Classen J, Bamberg M. Radiotherapy alone in technically operable, medically inoperable, early-stage (I/II) non-small-cell lung cancer. Int J Radiat Oncol Biol Phys. 2002;54(1):119-130. doi:10.1016/s0360-3016(02)02917-6

19. Zimmermann FB, Geinitz H, Schill S, et al. Stereotactic hypofractionated radiation therapy for stage I non-small cell lung cancer. Lung Cancer. 2005;48(1):107-114. doi:10.1016/j.lungcan.2004.10.015

20. Nagata $Y$, Wulf J, Lax I, et al. Stereotactic radiotherapy of primary lung cancer and other targets: results of consultant meeting of the International Atomic Energy Agency. Int J Radiat Oncol Biol Phys. 2011;79(3):660-669. doi:10.1016/j.jijobp.2010.10.004

21. Timmerman RD, Herman J, Cho LC. Emergence of stereotactic body radiation therapy and its impact on current and future clinical practice. J Clin Oncol. 2014;32(26):2847-2854.

doi:10.1200/JCO.2014.55.4675

22. Patel SH, Ma Y, Wernicke AG, Nori D, Chao KS, Parashar B. Evidence supporting contemporary postoperative radiation therapy (PORT) using linear accelerators in N2 lung cancer. Lung Cancer. 2014;84(2):156-160. doi:10.1016/j.lungcan.2014.02.016

23. Postoperative radiotherapy in non-small-cell lung cancer: systematic review and meta-analysis of individual patient data from nine randomized controlled trials. PORT Meta-analysis Trialists Group. Lancet.1998 Jul 25;352(9124):257-63.

24. Burdett S, Rydzewska L, Tierney J, et al. Postoperative radiotherapy for non-small cell lung cancer. Cochrane Database Syst Rev. 2016;10(10):CD002142. Published 2016 Oct 11. doi:10.1002/14651858.CD002142.pub4 
25. Bezjak A, Temin S, Franklin G, Giaccone G, Govindan R, Johnson ML, Rimner A, Schneider BJ, Strawn J, Azzoli CG Definitive and Adjuvant Radiotherapy in Locally Advanced Non-Small-Cell Lung Cancer: American Society of Clinical Oncology Clinical Practice Guideline Endorsement of the American Society for Radiation Oncology Evidence-Based Clinical Practice Guideline. JClinOncol.2015 Jun 20;33(18):2100-5.

26. Jeremic B, Casas F, Dubinsky P, Cihoric N, Gomez-Caamano A. The Trimodality Treatment Approach in Stage III/pN2 Non-Small Cell Lung Cancer: "Usually Appropriate" May Well be a Very Inappropriate Treatment Option. Am J Clin Oncol. 2015;38(6):645. doi:10.1097/COC.0000000000000223

27. Jeremic B, Casas F, Dubinsky P, Gomez-Caamano A, Čihorić N, Videtic G, Latinovic M. Combined modality therapy in Stage IIIA non-small cell lung cancer: clarity or confusion despite the highest level of evidence? J Radiat Res. 2017 May; 58(3): 267-272.

28. Jeremić B, Casas F, Dubinsky P, et al. Treatment-Related Predictive and Prognostic Factors in Trimodality Approach in Stage IIIA/N2 Non-Small Cell Lung Cancer. Front Oncol. 2018;8:30. Published 2018 Feb 20. doi:10.3389/fonc.2018.00030

29. Jeremić B. Induction Therapies Plus Surgery Versus Exclusive Radiochemotherapy in Stage IIIA/N2 Non-Small Cell Lung Cancer (NSCLC). Am J Clin Oncol. 2018;41(3):267-273. doi:10.1097/COC.0000000000000416.

30. Jeremić B, Casas F, Dubinsky P, Gomez-Caamano A, Čihorić N, Videtic G. Surgery for Stage IIIA NonSmall-cell Lung Cancer: Lack of Predictive and Prognostic Factors Identifying Any Subgroup of Patients Benefiting From It. Clin Lung Cancer. 2016;17(2):107-112. doi:10.1016/j.cllc.2015.11.001.

31. Aupérin A, Le Péchoux $C$, Rolland E, et al. Meta-analysis of concomitant versus sequential radiochemotherapy in locally advanced non-small-cell lung cancer. J Clin Oncol. 2010;28(13):21812190. doi:10.1200/JCO.2009.26.2543

32. Liang HY, Zhou H, Li XL, Yin ZH, Guan P, Zhou BS. Chemo-radiotherapy for advanced non-small cell lung cancer: concurrent or sequential? It's no longer the question: a systematic review. Int $J$ Cancer. 2010;127(3):718-728. doi:10.1002/ijc.25087.

33. O'Rourke N, Roqué I Figuls $M$, Farré Bernadó N, Macbeth F. Concurrent chemoradiotherapy in nonsmall cell lung cancer. Cochrane Database Syst Rev. 2010;(6):CD002140. Published 2010 Jun 16. doi:10.1002/14651858.CD002140.pub3.

34. Bradley JD, Paulus R, Komaki R, et al. Standard-dose versus high-dose conformal radiotherapy with concurrent and consolidation carboplatin plus paclitaxel with or without cetuximab for patients with stage IIIA or IIIB non-small-cell lung cancer (RTOG 0617): a randomised, two-by-two factorial phase 3 study. Lancet Oncol. 2015;16(2):187-199. doi:10.1016/S1470-2045(14)71207-0

35. Palma DA, Olson R, Harrow $S$, et al. Stereotactic ablative radiotherapy versus standard of care palliative treatment in patients with oligometastatic cancers (SABR-COMET): a randomised, phase 2, open-label trial. Lancet. 2019;393(10185):2051-2058. doi:10.1016/S0140-6736(18)32487-5

36. Gomez DR, Tang C, Zhang J, et al. Local Consolidative Therapy Vs. Maintenance Therapy or Observation for Patients With Oligometastatic Non-Small-Cell Lung Cancer: Long-Term Results of a 
Multi-Institutional, Phase II, Randomized Study. J Clin Oncol. 2019;37(18):1558-1565.

doi:10.1200/JC0.19.00201.

37. Guckenberger M, Lievens $Y$, Bouma AB, et al. Characterisation and classification of oligometastatic disease: a European Society for Radiotherapy and Oncology and European Organisation for Research and Treatment of Cancer consensus recommendation. Lancet Oncol. 2020;21(1):e18-e28. doi:10.1016/S1470-2045(19)30718-1.

38. Levy A, Hendriks LEL, Berghmans T, et al. EORTC Lung Cancer Group survey on the definition of NSCLC synchronous oligometastatic disease. Eur J Cancer. 2019;122:109-114. doi:10.1016/j.ejca.2019.09.012.

39. Dingemans AC, Hendriks LEL, Berghmans T, et al. Definition of Synchronous Oligometastatic NonSmall Cell Lung Cancer-A Consensus Report. J Thorac Oncol. 2019;14(12):2109-2119. doi:10.1016/j.jtho.2019.07.025.

40. Jeremic B. Timing of concurrent radiotherapy and chemotherapy in limited-disease small-cell lung cancer: "Meta-analysis of meta-analyses". Int J Radiat Oncol Biol Phys. 2006;64(4):981-982. doi:10.1016/j.jirobp.2005.10.034.

41. Turrisi AT 3rd, Kim K, Blum R, et al. Twice-daily compared with once-daily thoracic radiotherapy in limited small-cell lung cancer treated concurrently with cisplatin and etoposide. N Eng/ J Med. 1999;340(4):265-271. doi:10.1056/NEJM199901283400403.

42. Jeremic B, Shibamoto $Y$, Acimovic $L$, et al. Initial versus delayed accelerated hyperfractionated radiation therapy and concurrent chemotherapy in limited small cell lung cancer. J Clin Oncol 1997; 15: 893-900.

43. Murray N, Coy P, Pater JL, Hodson I, Arnold A, Zee BC, Payne D, Kostashuk EC, Evans WK, Dixon P, et al. Importance of timing for thoracic irradiation in the combined modality treatment of limited-stage small-cell lung cancer. The National Cancer Institute of Canada Clinical Trials Group. JClinOncol. 1993Feb;11(2):336-44.

44. Faivre-Finn C, Snee M, Ashcroft L, et al. Concurrent once-daily versus twice-daily chemoradiotherapy in patients with limited-stage small-cell lung cancer (CONVERT): an open-label, phase 3, randomised, superiority trial. Lancet Oncol. 2017;18(8):1116-1125. doi:10.1016/S1470-2045(17)30318-2

45. Aupérin A, Arriagada R, Pignon JP, et al. Prophylacticcranial irradiation for patients with small-cell lung cancer in complete remission. Prophylactic Cranial Irradiation Overview Collaborative Group. NEngl J Med. 1999; 341: 476-84.

46. Le Péchoux C, Dunant A, Senan S, et al. Standard-dose versus higher-dose prophylactic cranial irradiation $(\mathrm{PCl})$ in patients with limited-stage small-cell lung cancer in complete remission after chemotherapy and thoracic radiotherapy (PCI 99-01, EORTC 22003-08004, RTOG 0212, and IFCT 9901): a randomised clinical trial. Lancet Oncol. 2009;10(5):467-474. doi:10.1016/S14702045(09)70101-9.

47. Jeremic B, Shibamoto $Y$, Nikolic N, et al. Role of radiation therapy in the combined-modality treatment of patients with extensive disease small-cell lung cancer: A randomized study. J Clin 
Oncol. 1999;17(7):2092-2099. doi:10.1200/JC0.1999.17.7.2092

48. Slotman BJ, van Tinteren $\mathrm{H}$, Praag JO, et al. Use of thoracic radiotherapy for extensive stage smallcell lung cancer: a phase 3 randomised controlled trial [published correction appears in Lancet. 2015 Jan 3;385(9962):28]. Lancet. 2015;385(9962):36-42. doi:10.1016/S0140-6736(14)61085-0.

49. Gore EM, Hu C, Sun AY, et al. Randomized Phase II Study Comparing Prophylactic Cranial Irradiation Alone to Prophylactic Cranial Irradiation and Consolidative Extracranial Irradiation for ExtensiveDisease Small Cell Lung Cancer (ED SCLC): NRG Oncology RTOG 0937. J Thorac Oncol. 2017;12(10):1561-1570. doi:10.1016/j.jtho.2017.06.015.

50. Takahashi T, Yamanaka T, Seto T, et al. Prophylactic cranial irradiation versus observation in patients with extensive-disease small-cell lung cancer: a multicentre, randomised, open-label, phase 3 trial. Lancet Oncol. 2017;18(5):663-671. doi:10.1016/S1470-2045(17)30230-9.

51. Slotman B, Faivre-Finn C, Kramer G, et al. Prophylactic cranial irradiation in extensive small-cell lung cancer. N Engl J Med. 2007;357(7):664-672. doi:10.1056/NEJMoa071780.

\section{Figures}

\section{Rate of recommended molecular testing in clinical practice}

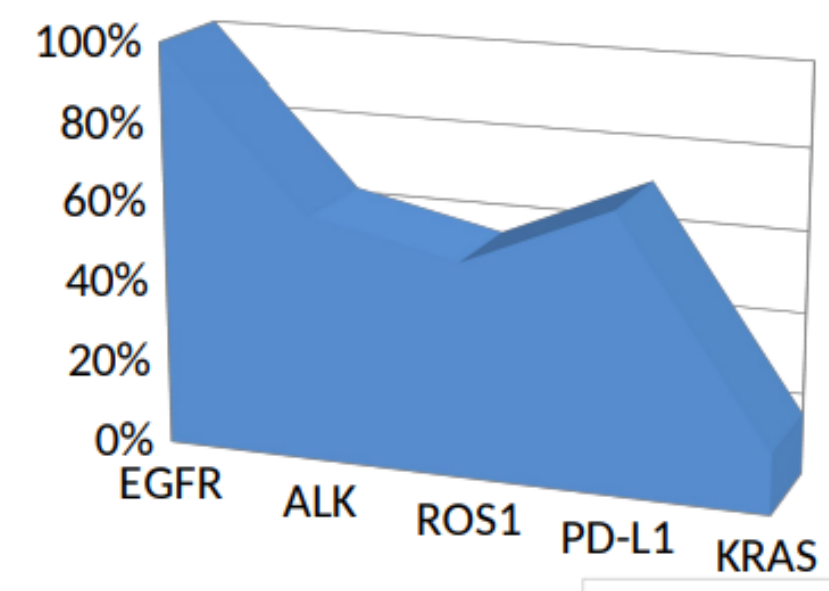

Rate of markers which are recommended in clinical practice 
Figure 1

a) Rate of recommended molecular testing in clinical practice b) Rate of markers which are recommended in clinical practice

\section{Advanced NSCLC $\quad$ SCLC}

\begin{tabular}{|c|c|c|c|c|c|}
\hline EGFR mut & $\begin{array}{c}\text { ALK/ROS1 } \\
\text { trasnlocation }\end{array}$ & Non-squamous & Squamous & LD-SCLC & ED-SCLC \\
\hline \multicolumn{6}{|l|}{ First line } \\
\hline $\begin{array}{c}\text { Erlotinib } \\
\text { Osimertinib* } \\
\text { (with high co- } \\
\text { payment) }\end{array}$ & Crizotinib* & $\begin{array}{c}\text { Paclitaxel/carboplatin } \\
\text { OR } \\
\text { Platinum/pemetrexed } \\
\text { OR } \\
\text { Pacli/carbo/Bevacizumab* }\end{array}$ & $\begin{array}{c}\text { Cisplatin/gemcitabine } \\
\text { OR } \\
\text { Paclitaxel/carboplatin }\end{array}$ & $\begin{array}{c}\text { Cisplatin/ } \\
\text { etoposide } \\
\text { with TRT } \\
\text { followed by } \\
\text { PCI }\end{array}$ & $\begin{array}{c}\text { Cisplatin/ } \\
\text { etoposide } \\
+/- \\
\text { TRT (in } \\
\text { responders) }\end{array}$ \\
\hline \multicolumn{6}{|l|}{ Second line } \\
\hline $\begin{array}{c}\text { Osimertinib* } \\
\text { OR } \\
\text { Platinum based } \\
\text { chemotherapy }\end{array}$ & Chemotherapy & $\begin{array}{l}\text { Mono chemotherapy with } \\
\text { Pemetrexed, Docetaxel, } \\
\text { or Vinorelbin }\end{array}$ & $\begin{array}{l}\text { Mono chemotherapy } \\
\text { with Docetaxel, } \\
\text { Gemcitabine or } \\
\text { Vinorelbin }\end{array}$ & $\begin{array}{c}\text { Topotecan } \\
\text { or } \\
\text { Irinotecan }\end{array}$ & $\begin{array}{c}\text { Topotecan } \\
\text { or } \\
\text { Irinotecan }\end{array}$ \\
\hline & & & & & \\
\hline
\end{tabular}

EGFR -epidermal growth factor receptor, ALK- anaplastic lymphoma kinase, ROS1 - ROS Proto-Oncogene 1, Receptore Tyrosine kinase.

Limited access, with high co-payment *

Figure 2

Treatment algorithm for advance NSCLC and LD/ED-SDLC (Available treatment approaches)

\section{Supplementary Files}

This is a list of supplementary files associated with this preprint. Click to download.

- questionnaire.docx 